\title{
МЕТОДИКА ЕКСПЕРИМЕНТАЛЬНОГО ДОСЛІДЖЕННЯ ЗЧЕПЛЕННЯ АРМАТУРИ 3 ФІБРОБЕТОНОМ
}

\author{
METHODS OF EXPERIMENTAL STUDIES OF REBAR \\ REINFORCEMENT AND FIBER CONCRETE ADHESION
}

\begin{abstract}
Андрійчук О.В., к.т.н., доц. (Луцький національний технічний університет), Швець І.В. аспірант (Національний університет водного господарства та природокористування, м. Рівне)
\end{abstract}

\begin{abstract}
Andriichuk O.V., Ph.D., associate professor, (Lutsk National Technical University), Shvetc I.V., postgraduate student (National University of Water Management and Natural Resources, Rivne)
\end{abstract}

\begin{abstract}
Анотація. $У$ статті представлено методику проведення експериментального дослідження зі встановлення особливостей зчеплення арматури серпоподібного профілю $з$ дисперсно-армованими бетонами сталефібробетоном $i$ фібробетоном на основі базальтової фібри. Метою дослідження $\epsilon$ побудова математичних моделей для визначення граничних напружень зчеплення та аналіз впливу визначальних факторів на напруження зчеплення по поверхні контакту арматури з фібробетоном.
\end{abstract}

Summary. The article describes the method of experimental research on the determination of the peculiarities of the adhesion of sickle-shaped profile rebar with dispersion-reinforced concretes - steel fiber reinforced concrete (SFRC) and fiber concrete on the basis of basalt fiber.

The purpose of the research is to determine the peculiarities of the adhesion of the sickle-shaped profile rebar with SFRC and fiber concrete on the basis of basalt fiber, the construction of mathematical models to determine the limiting stresses of the adhesion and the analysis of the influence of determining factors on the adhesion stress of the surface contact of the rebar reinforcement with the fiber concrete.

The adhesion of rebar with concrete and its anchoring - fixing the ends of the rods in the concrete - significantly affects the reliability of reinforced concrete structures. The adhesion of rebar with plain concrete is studied and there are mathematical models for determining the ultimate stresses, but adhesion of rebar with fiber concrete have not yet been conducted in Ukraine.

Although the fiber concrete itself is increasingly used in reinforced concrete structures, in which it is necessary to ensure reliable anchoring of rebar.

Fiber concretes, as well as concretes, belong to the number of poorly organized or so-called diffuse systems, the characteristic features of which are the impossibility to clear selection of separate phenomena and the need to take into account many mixed factors. With regard to the adhesion of rebar to concrete, the system "concrete reinforcement" can be considered as a diffuse system. The regression equation is obtained on the basis of mathematical modeling, as a result of which it is possible to 
obtain the surface of feedback factors. The most convenient is the representation of the unknown response function in the form of polynomials.

The main factors that significantly affect the anchoring stress of reinforcement with fiber concrete can be taken as the percentage of fiber content, diameter of rebars, length of anchoring rebars in the concrete. These factors are not correlated with each other. As it is known that concrete is an elastic-plastic material, which has curvilinear diagrams of the mechanical state, let's choose the Box-Behnken design for obtaining the quadratic dependences (quadratic mathematical model).

The experimental samples will be made of C25/30 fine-grained concrete. Based on the results of the experiments, the following will be performed: their statistical processing; mathematical models will be constructed; the influence of the accepted factors will be analyzed; the table of calculated values of the rebar and fiber concrete anchoring strengths will be presented.

Ключові слова: бетон, сталева фібра, СФБ, сталефібробетон, арматура, зчеплення, напруження.

Keywords: concrete, steel fiber, SFRC, steel fiber reinforced concrete, fittings, couplings, tension.

Постановка проблеми. Вимоги щодо збільшення терміну експлуатації залізобетонних конструкцій спонукають до дослідження та удосконалення їх армування. В якості армуючого матеріалу останнім часом все більш широкого застосування набуває дисперсне армування волокнами. Для їх виготовлення використовуються різні матеріали: метал, базальт, поліпропілен, скло та ін. Ідея підсилення звичайного бетону його армуванням по всьому своєму об'єму металевими і неметалевими волокнами - фіброволокном, виникла понад 100 років тому [1]. Дисперсне фіброве армування дозволяє компенсувати головні недоліки бетону низьку міцність на розтяг і тріщиностійкість, та крихкість руйнування.

3 усіх видів дисперсних бетонів найбільш масовим є сталефібробетон (СФБ), що являє собою бетон, армований рівномірно розподіленими в його об’ємі сталевими фібрами з оптимальною довжиною $l=50$ мм.

Раціонально використовувати СФБ для тонкостінних конструкцій покриттів і стінових огороджувальних елементів, елементів, що працюють в умовах просторового напружено-деформованого стану, в попередньонапружених конструкціях з метою підвищення анкерування арматури, в інженерних спорудах (днища резервуарів, безнапірні труби, водовідвідні лотки), для підлог виробничих будівель, дорожніх та аеродромних покриттів, у палях і фундаментах під технологічне обладнання, для захисних екранів, хвилерізів, молів і набережних, у фортифікаційних спорудах, при підсиленні тріщиностійкості конструкцій тощо.

Аналіз досліджень і публікацій. Значна кількість українських [2-5] i іноземних [6-7] науковців досліджують СФБ і отримують актуальні та затребувані результати. 
Особливої уваги заслуговують дослідження конструкцій iз комбінованим армуванням - поєднання класичного залізобетону та дисперсно розташованих в його об'ємі фібр (сталевих чи базальтових). Переваги дисперсно-армованих конструкцій можуть реалізовуватися при врахуванні фактичних характеристик фібр у розрахункових станах елементів конструкцій на прогин, на дію поздовжньої і поперечної сил, а також при встановленні величини ширини розкриття тріщин.

У праці [8] представлено результати теоретичних досліджень параметрів попередньо-напруженої дисперсно-армованої залізобетонної прогонової мостової будови довжиною $L p=66 \mathrm{~m}$ із висотою балки $h=3,75$ м і площею іiі січення $S=6,133 \mathrm{~m}^{2}$. Дані мостові балки були запроектовані з бетону класу C32/40 для високошвидкісних залізничних магістралей в умовах сухого та спекотного клімату Узбекистану. Порівняльна оцінка величини зменшення втрати напруження при застосуванні дисперсно-армованої конструкції, за даними розрахункового аналізу, дозволила виявити переваги та ефективність роботи високоміцної арматури з металевою фіброю. Сумарні втрати напруження в арматурі, в порівнянні 3 класичним попередньо напруженим залізобетоном, були скорочені на основі одержаного порівняльного розрахунку аж на $25,8 \%$.

Зчеплення арматури з бетоном та іiі анкерування - закріплення кінців стержнів в бетоні - суттєво впливає на надійність залізобетонних конструкцій і $є$ визначальним фактором у забезпеченні їхньої спільної роботи в складі залізобетонних конструкцій. Анкерування арматури періодичного профілю всередині бетону в основному забезпечується силами зчеплення, які залежать від багатьох факторів, а тому і надійність анкерування арматури залежить також від багатьох факторів.

Варто відмітити, що зчеплення арматури зі звичайним бетоном вже $\epsilon$ вивченим [9], теорія розроблена в достатній мірі і $є$ математичні моделі для визначення граничних напружень [10]. Із фібробетоном такі досліди не проводилися, хоча самі фібробетони набувають все ширшого застосування в залізобетонних конструкціях, у яких необхідно забезпечувати надійне анкерування арматури. А для його вивчення необхідно проводити значні експериментальні дослідження зчеплення арматури серповидного профілю 3 фібробетонами (рис. 1).

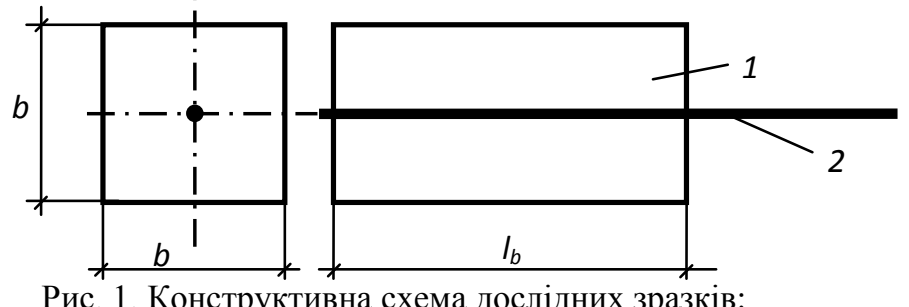

Рис. 1. Конструктивна схема дослідних зразків:

1 - бетонна призма; 2 - арматурний стержень 
Метою дослідження $€$ встановлення особливостей зчеплення арматури серпоподібного профілю зі СФБ та 3 фібробетоном на основі базальтової фібри; побудова математичних моделей для визначення граничних напружень зчеплення; аналіз впливу визначальних факторів на напруження зчеплення по поверхні контакту арматури з фібробетоном.

Фібробетони, як і бетони, відносяться до числа погано організованих або так званих дифузних систем, характерними рисами яких $\epsilon$ неможливість чіткого виділення окремих явищ і необхідність урахування багатьох різнорідних факторів. Стосовно зчеплення арматури з бетоном систему «бетон - арматура» також можна розглядати як дифузну систему. Для дифузних систем, в умовах неповного знання механізму всього явища зчеплення, особливо ефективним є статистичний метод дослідження. Він дозволяє розробляти рекомендації з оптимальної поведінки системи в умовах невизначеності і представляти експериментальний матеріал у формі аналітичного виразу (рівняння регресіі).

Отримання рівняння регресії здійснюється на основі математичного моделювання, внаслідок якого можна отримувати поверхню відгуків факторів. Найбільш зручним є представлення невідомої функції відгуку у вигляді поліномів. Відповідно до сучасної математичної моделі експерименту найбільш вдале поєднання статистичного і кібернетичного підходів до дослідження дифузних систем має місце в методах математичного планування експерименту.

Методика та план експериментальної частини дослідження. Основними факторами, які суттєво впливають на напруження зчеплення арматури 3 фібробетоном, $\epsilon$ відсоток вмісту фібр $\left(x_{l}\right.$, \%), діаметр арматурних стержнів $\left(x_{2}, d\right)$, довжина закріплення стержнів в бетоні $\left(x 3, l_{b}\right.$ - довжина анкерування). Ці фактори не мають між собою кореляції. 3 цього випливає, що переважно необхідно вибрати трьохфакторний план експерименту. Оскільки відомо, що бетон $є$ пружно-пластичним матеріалом, якому притаманні криволінійні діаграми механічного стану, необхідно вибирати плани для отримання квадратичних залежностей (квадратичної математичної моделі). Наведеним вимогам відповідає матриця плану Бокса-Бенкіна.

За граничний стан зчеплення арматури з бетоном приймається стан, коли проковзування (переміщення) вільного кінця стержня відносно торця призм складає $\delta_{u}=0,2$ мм $[9,10]$.

Для проведення експериментальної частини дослідження зчеплення арматури з фібробетоном розроблено планований експеримент на основі матриці плану Бокса-Бенкіна. Умови для дослідження зчеплення арматури зі сталефібробетоном (серія 1) представлено у табл. 1, а для дослідження зчеплення арматури з базальтофібробетоном - у табл. 2. Завдяки цьому буде оптимізовано (зменшено) на 44\% кількість експериментальних зразків - із 162 до 90 елементів. 
Таблиця 1.

Умови планування експерименту для дослідження зчеплення арматури з сталефібробетоном (перша серія)

\begin{tabular}{|c|c|c|c|c|c|}
\hline \multicolumn{2}{|c|}{ Фактори } & \multicolumn{3}{|c|}{ Рівні варіювання } & \multirow{2}{*}{$\begin{array}{c}\text { Інтервал } \\
\text { варіювання }\end{array}$} \\
\cline { 1 - 4 } $\begin{array}{c}\text { Натуральний } \\
\text { вигляд }\end{array}$ & $\begin{array}{c}\text { Кодований } \\
\text { вигляд }\end{array}$ & -1 & 0 & +1 & 0,6 \\
\hline $\begin{array}{c}\text { Процент вмісту } \\
\text { фібр, \% }\end{array}$ & $x_{1}$ & 0,6 & 1,2 & 1,8 & 4 \\
\hline $\begin{array}{c}\text { Діаметр } \\
\text { стержнів, } d, \text { мм }\end{array}$ & $x_{2}$ & 12 & 16 & 20 & $2,5 d$ \\
\hline $\begin{array}{c}\text { Довжина } \\
\text { анкерування, } l_{b}\end{array}$ & $x_{3}$ & $5 d$ & $7,5 d$ & $10 d$ & 2,5 \\
\hline
\end{tabular}

Таблиця 2.

Умови планування експерименту для дослідження зчеплення арматури 3 базальтофібробетоном (друга серія)

\begin{tabular}{|c|c|c|c|c|c|}
\hline \multicolumn{2}{|c|}{ Фактори } & \multicolumn{3}{|c|}{ Рівні варіювання } & \multirow{2}{*}{$\begin{array}{c}\text { Інтервал } \\
\text { варіювання }\end{array}$} \\
\cline { 1 - 4 } $\begin{array}{c}\text { Натуральний } \\
\text { вигляд }\end{array}$ & $\begin{array}{c}\text { Кодований } \\
\text { вигляд }\end{array}$ & -1 & 0 & +1 & 1,5 \\
\hline $\begin{array}{c}\text { Процент вмісту } \\
\text { фібр, \% }\end{array}$ & $x_{1}$ & 0,5 & 1,5 & 2,5 & 4 \\
\hline $\begin{array}{c}\text { Діаметр } \\
\text { стержнів, } d, \text { мм }\end{array}$ & $x_{2}$ & 12 & 16 & 20 & $2,5 d$ \\
\hline $\begin{array}{c}\text { Довжина } \\
\text { анкерування, } l_{b}\end{array}$ & $x_{3}$ & $5 d$ & $7,5 d$ & $10 d$ & \\
\hline
\end{tabular}

Експериментальні дослідні зразки (призми) виготовляються 3 дрібнозернистого бетону класу С25/30. Поряд із призмами виготовляються по три кубики $10 \times 10 \times 10 \mathrm{~cm}$ із бетону матриці, базальтофібробетону (БФБ) та сталефібробетону (СФБ).

На основі умов планування експерименту (табл. 1 і табл. 2) розроблено матриці плану Бокса-Бенкіна та вихідні експериментальні дані для першої серії дослідів (зчеплення в СФБ) і другої серії дослідів (зчеплення в БФБ) - представлено в табл. 3 і табл. 4 відповідно.

У точках плану 1 - 13 (табл. 3 і табл. 4) виконується по три досліди. Додатково виконується шість дослідів із зразками з бетону матриці та стержнями діаметром $d=16$ мм і довжиною анкерування $l_{b}=60$ мм i $l_{b}=90 \mathrm{MM}$. 
Таблиця 3. Матриця плану Бокса-Бенкіна та вихідні експериментальні дані для першої серії дослідження (зчеплення в СФБ)

\begin{tabular}{|c|c|c|c|c|c|c|}
\hline \multirow{2}{*}{$\begin{array}{c}\text { Точки } \\
\text { плану }\end{array}$} & \multicolumn{3}{|c|}{ Матриця планування } & \multicolumn{3}{c|}{$\begin{array}{c}\text { Матриця планування в } \\
\text { натуральних величинах }\end{array}$} \\
\cline { 2 - 7 } & $\mathrm{x} 1$ & $\mathrm{x} 2$ & $\mathrm{x} 3$ & $\mathrm{x} 1, \%$ & $\mathrm{x} 2$, мм & $\mathrm{x} 3, \boldsymbol{M м}$ \\
\hline 1 & +1 & +1 & 0 & 1,8 & 20 & 150 \\
\hline 2 & +1 & -1 & 0 & 1,8 & 12 & 90 \\
\hline 3 & -1 & +1 & 0 & 0,6 & 20 & 150 \\
\hline 4 & -1 & -1 & 0 & 0,6 & 12 & 90 \\
\hline 5 & +1 & 0 & +1 & 1,8 & 16 & 160 \\
\hline 6 & +1 & 0 & -1 & 1,8 & 16 & 80 \\
\hline 7 & -1 & 0 & +1 & 0,6 & 16 & 160 \\
\hline 8 & -1 & 0 & -1 & 0,6 & 16 & 80 \\
\hline 9 & 0 & +1 & +1 & 1,2 & 20 & 200 \\
\hline 10 & 0 & +1 & -1 & 1,2 & 20 & 100 \\
\hline 11 & 0 & -1 & +1 & 1,2 & 12 & 120 \\
\hline 12 & 0 & -1 & -1 & 1,2 & 12 & 60 \\
\hline 13 & 0 & 0 & 0 & 1,2 & 16 & 120 \\
\hline
\end{tabular}

Таблиця 4.

Матриця плану Бокса-Бенкіна та вихідні експериментальні дані для другої серії дослідження (зчеплення в БФБ)

\begin{tabular}{|c|c|c|c|c|c|c|}
\hline \multirow{2}{*}{$\begin{array}{c}\text { Точки } \\
\text { плану }\end{array}$} & \multicolumn{3}{|c|}{ Матриця планування } & \multicolumn{3}{c|}{$\begin{array}{c}\text { Матриця планування в } \\
\text { натуральних величинах }\end{array}$} \\
\cline { 2 - 7 } & $x_{1}$ & $x_{2}$ & $x_{3}$ & $f_{b 1}$ & $f_{b 2}$ & $f_{b 3}$ \\
\hline 1 & +1 & +1 & 0 & 2,5 & 20 & 150 \\
\hline 2 & +1 & -1 & 0 & 2,5 & 12 & 90 \\
\hline 3 & -1 & +1 & 0 & 0,5 & 20 & 150 \\
\hline 4 & -1 & -1 & 0 & 0,5 & 12 & 90 \\
\hline 5 & +1 & 0 & +1 & 2,5 & 16 & 160 \\
\hline 6 & +1 & 0 & -1 & 2,5 & 16 & 80 \\
\hline 7 & -1 & 0 & +1 & 0,5 & 16 & 160 \\
\hline 8 & -1 & 0 & -1 & 0,5 & 16 & 80 \\
\hline 9 & 0 & +1 & +1 & 1,5 & 20 & 200 \\
\hline 10 & 0 & +1 & -1 & 1,5 & 20 & 100 \\
\hline 11 & 0 & -1 & +1 & 1,5 & 12 & 120 \\
\hline 12 & 0 & -1 & -1 & 1,5 & 12 & 60 \\
\hline 13 & 0 & 0 & 0 & 1,5 & 16 & 120 \\
\hline
\end{tabular}

На основі отриманих результатів дослідження буде виконано: статистичну обробку результатів дослідження; побудовано математичні 
моделі; виконано аналіз впливу прийнятих факторів на зчеплення; складено таблицю розрахункових значень напружень зчеплення арматури зі стале- та базальтофібробетоном.

У планованих експериментах першої і другої серій не передбачалося дослідження впливу міцності бетону на величину напружень зчеплення 3 арматурою, оскільки для цього фактору дуже трудомістко встановити i забезпечити однаковий інтервал варіювання для $(-1)$ i $(+1)$. Тому цей вплив можна дослідити, виконуючи «класичний» однофакторний окремий експеримент. Це буде реалізовано при виконанні третьої серії дослідів.

В експериментах третьої серії передбачається зафіксувати на певній величині фактори, які досліджені в перших двох серіях, а варіювати міцність матриці фібробетону. Досліджені фактори доцільно зафіксувати на оптимальних значеннях, а саме: діаметр арматури приймається $d=16$ мм; довжина анкерування $-7,5$ діаметра або $l_{b}=120$ мм; відсоток армування (за об'ємом) фібрами - 1,5\%. Варіюванню підлягає міцність бетонної матриці, яка повинна наближатися до міцності бетонів класів C20/25, C25/30 i C30/35.

Висновки. Розроблена методика експериментального дослідження зчеплення арматури 3 фібробетоном забезпечить отримання нових наукових результатів із необхідною достовірністю.

Застосування планованого експерименту (на основі матриці плану Бокса-Бенкена) оптимізує (зменшить) на 44\% кількість експериментальних зразків - із 162 до 90 елементів.

Результати досліджень, проведених за поданою методикою, будуть використані при конструюванні згинальних залізобетонних елементів із частковим (пошаровим) дисперсним армуванням.

\section{References}

1. Nekrasov V.P. Metod kosvennoho vooruzhenyia betona: Novyi zhelezobeton / V.P. Nekrasov. - M.: NKPS, Transpechat, 1925. -255 s.

2. Babych E.M. Strength of elements with annular cross sections made of steelfiber-reinforced concrete under one-time loads / O.V. Andriichuk, E.M. Babych // Materials Science, Vol. 52, No. 4, New York - 2017, p. 509-513.

3. R. Kinash, V. Bilozir. Deformational calculation method of bearing capability of fiber-concrete steel bending elements. Czasopismo Techniczne (2015).

4. Andriichuk $\mathrm{O}$. The impact of the reinforcement percentage on the stress-strain state of the bending steel fiber reinforced concrete elements/ Andriichuk O., Babich V., Yasyuk I., Uzhehov S. // MATEC Web of Conferences, N 230, p 02001 (2018), 1-5.

5. Uzhehov S.O. Vyznachennia optymalnykh rozmiriv konstruktyvnykh elementiv stalefibrobetonnoi konstruktsii pokryttia u formi hiperbolichnoho paraboloida / S.O. Uzhehov, R.V. Pasichnyk, O.V. Andriichuk // Resursoekonomni materialy, konstruktsii, budivli ta sporudy - Rivne: NUVHP, 2014. - Vypusk 29. - S. 506 - 511.

6. MAB Oliveira. Analysis of influence of concrete element format and properties steel fibers on flexural toughness / Oliveira, EMLS Ramos, DRC Oliveira, BBP Neto // Matéria (Rio J.) vol.23 no.3 Rio de Janeiro, SciELO Brasil, 2018 Epub 18-Out-2018 
7. Sameh Y 2018 Effect of steel fibers and GFRP sheet on the behavior of lightweight concrete specimens using waste lightweight sand bricks (International Journal of Engineering Research \& Technology, IJERT, 7 Issue 03) pp 69-75.

8. Chyzhov S.V. Pryntsypy rascheta predvarytelno napriazhennykh zhelezobetonnykh elementov proletnoho stroenyia pry dyspersnom armyrovanyy / S.V. Chyzhov, E.B. Shestakova, E.T. Yakhshyev, A.A. Antoniuk // Yzvestyia PHUPS: Sovremennye tekhnolohyy - transportu. - SPb, - 2017, №2. - S. 343 - 353.

9. Chapiuk O.S. Zcheplennia armatury $\mathrm{z}$ armaturnym prokatom serpovydnoho profiliu pry korotkochasnykh odnorazovykh i povtornykh navantazhenniakh: dys. ... kand. tekhn. nauk: 05.23.01 / Lutsk: LNTU, 2009. 169 s.

10. Babych Ye.M. Zcheplennia $\mathrm{z}$ betonom armatury serpopodibnoho profiliu ta yii ankeruvannia v zghynalnykh zalizobetonnykh elementakh: monohrafiia / Babych Ye.M., Babych V.Ie., Polianovska O.Ie. // NUVHP - Rivne: Volyn. oberehy, 2017. - 158 s.

\section{Список використаної літератури}

1. Некрасов В.П. Метод косвенного вооружения бетона: Новый железобетон / В.П. Некрасов. - М.: НКПС, Транспечать, 1925. -255 с.

2. Babych E.M. Strength of elements with annular cross sections made of steelfiber-reinforced concrete under one-time loads / O.V. Andriichuk, E.M. Babych // Materials Science, Vol. 52, No. 4, New York - 2017, p. 509 - 513.

3. R. Kinash, V. Bilozir. Deformational calculation method of bearing capability of fiber-concrete steel bending elements. Czasopismo Techniczne (2015).

4. Andriichuk $\mathrm{O}$. The impact of the reinforcement percentage on the stress-strain state of the bending steel fiber reinforced concrete elements/ Andriichuk O., Babich V., Yasyuk I., Uzhehov S. // MATEC Web of Conferences, N 230, p 02001 (2018), 1-5.

5. Ужегов С.О. Визначення оптимальних розмірів конструктивних елементів сталефібробетонної конструкції покриття у формі гіперболічного параболоїда / С.О. Ужегов, Р.В. Пасічник, О.В. Андрійчук // Ресурсоекономні матеріали, конструкції, будівлі та споруди - Рівне: НУВГП, 2014. - Випуск 29. - С. 506 - 511.

6. MAB Oliveira. Analysis of influence of concrete element format and properties steel fibers on flexural toughness / Oliveira, EMLS Ramos, DRC Oliveira, BBP Neto // Matéria (Rio J.) vol.23 no.3 Rio de Janeiro, SciELO Brasil, 2018 Epub 18-Out-2018

7. Sameh Y 2018 Effect of steel fibers and GFRP sheet on the behavior of lightweight concrete specimens using waste lightweight sand bricks (International Journal of Engineering Research \& Technology, IJERT, 7 Issue 03) pp 69-75.

8. Чижов С.В. Принципы расчета предварительно напряженных железобетонных элементов пролетного строения при дисперсном армировании / С.В. Чижов, Е.Б. Шестакова, Э.Т. Яхшиев, А.А. Антонюк // Известия ПГУПС: Современные технологии - транспорту. - СПб, - 2017, №2. - С. 343 - 353.

9. Чапюк О.С. Зчеплення арматури 3 арматурним прокатом серповидного профілю при короткочасних одноразових і повторних навантаженнях: дис. ... канд. техн. наук: 05.23.01 / Луцьк: ЛНТУ, 2009. 169 с.

10. Бабич С.М. Зчеплення з бетоном арматури серпоподібного профілю та іiі анкерування в згинальних залізобетонних елементах: монографія / Бабич С.М., Бабич В.Є., Поляновська О.Є. // НУВГП - Рівне: Волин. обереги, 2017. - 158 с. 